\title{
ATTENUATION OF THE PRESSOR RESPONSE TO TRACHEAL INTUBATION IN PREGNANT PATIENTS BY KETOROLAC DURING CAESAREAN SECTION
}

\author{
Osama M. Warda*, M.D., Mohamed R. El-Tahan **, M.D., Amr M. Yasseen*, \\ M.D., Magdy M. Attallah*, M.D., AND Mohamed K. Matter ${ }^{\prime}$, M.D. \\ From the Department of Obstetrics And Gynaecology*, the Department of Anaesthesia And \\ Surgical ICU**, and the Department of Paediatrics ${ }^{1}$, Faculty of Medicine, Mansoura University, \\ Mansoura, Egypt.
}

\section{ABSTRACT}

Objectives: ketorolac may attenuate maternal stress response to tracheal intubation, without subsequent dangers of opioid-induced neonatal depression. The objective of this study is to evaluate the haemodynamic and hormonal ellects of pre-emptive ketorolac on surgical stress and the postoperative analgesic consumption, after Cacsarean delivery.

Study Design: A prospective randomized double-blinded placebo-controlled study.

Methods: After ethical approval, 90 patients scheduled for elective Cacsarean deliveries were randomly allocated to the ketorolac group ( $n=45$ ); received IV ketorolac $15 \mathrm{mg}$ bolus, followed by an infusion of $7.5 \mathrm{mg} \cdot \mathrm{h}^{-1}$, and the saline for placebo group ( $n=45$ ). Anaesthesia was maintained with $50 \%$ nitrous oxide, $0.5 \%$ isollurane, and vecuronium. The haemodynamic variables and the levels of plasma cortisol were recorded before and after induction, and after delivery. The graded uterine relaxation, the need for supplementary doses of oxytocin, the peri-operative blood loss, bleeding time, and Apgar scores at 1 and 5 minutes, postoperative pain scores at rest and with movement, and tramadol consumptions were assessed.

Results: After intubation, parturients receiving ketorolac had a smaller increase in heart rate, systolic and mean arterial blood pressure $(\mathrm{P}<0.001)$ and lower plasma cortisol concentrations, $\left(45 \pm 15.1\right.$ vs. $\left.32.2 \pm 7.61 \mu \mathrm{g}, \mathrm{dl}^{-1}, \mathrm{P}<0.05\right)$. Therefore, they had lower VAS pain scores at rest and on movement, for the first 2 post-operative hours $(P<0.001)$, later time to first request for analgesia and less tramadol consumption for the first 4 post-operative hours $[0(0-100) \mathrm{mg}$ vs. $100(0-100) \mathrm{mg}, \mathrm{P}=0.004]$. There were no differences between groups with regard to peri-operative blood loss, bleeding time, transfusion requirements, nausea, vomiting or Apgar scores, with no evidence of premature closure of the ductus arteriosus of the newborns.

Conclusion: Pre-emptive ketorolac is safe and effective in attenuating the maternal stress response with improved quality of post-operative analgesia in Caesarean delivery patients.

Key words: Anaesthesia, Caesarean section, stress response, ketorolac.

\section{INTRODUCTION}

Pain relief of good quality after Caesarean section results in early mobilization and good early mother-child interaction. Increased sympathetic nervous system activity and plasma concentrations of catecholamines after tracheal intubation, in women having Caesarean delivery, may decrease placental perfusion and utcrine blood flow by $20 \%-35 \%$ (1) Opioid analgesia gives a very high level of patient satisfaction. Opioids are routinely omitted at the induction of general anaesthesia for Caesarean

Corresponding author : Osama M. Warda, MD, Obstetric And Gynaecology Department, Mansoura University, Mansoura, Egypt; E-mail: osamawarda@hotmail.com. 
delivery because of concerns about the placental transfer of drugs resulting in neonatal respiratory depression $^{(2)}$. The use of non-steroidal antiinflammatory drugs [NSAIDs] reduces the need for opioids significantly after Caesarean section with reduced risk of negative side-effects ${ }^{(3)}$. Therefore, intravenous pre-emptive tenoxicam significantly reduces the haemodynamic variability of light general anaesthesia at induction-delivery and twenty-four hours postoperative opioid consumption in patients undergoing Caesarean delivery without increasing side effects $^{(4)}$. Ketorolac given intravenously is as effective as morphine in the management of surgical pain, and it has fewer side effects ${ }^{(5)}$. The U.S. Food and Drug Administration currently does not approve the use of ketorolac in breastfeeding patients, even though the American Academy of Pediatrics has found ketorolac to be compatible with breastfeeding ${ }^{(6)}$.

We postulated that the use of ketorolac before the induction of anaesthesia for uncomplicated Caesarean section would reduce the maternal stress response after tracheal intubation and the postoperative analgesic consumption, without subsequent harmful effects to both the mother and the neonate. Therefore, the present study was designed to evaluate the effects of ketorolac on surgical stress and the postoperative analgesic consumption, after Caesarean delivery.

\section{MATERIALS \& METHODS}

\section{Patients:}

This prospective randomized double-blinded placebo-controlled study was carried out from March 2005 to October 2006 after approval of the Institutional Ethical Committee of Mansoura University Hospitals. After written informed consent was obtained, we studied ninety ASA I \& II women aged 20-35 years, with uncomplicated, singleton pregnancies of at least 36 weeks gestation, undergoing elective lower segment Caesarean sectıon [LSCS], with Pfannenstiel incision, under general anaesthesia. The indications for Caesarean delivery were breech presentation, cephalo-pelvic disproportion, or previous Caesarean delivery. Patients with a history of allergy to non-steroidal anti-inflammatory agents, bleeding tendency. bronchial asthma, peptic ulcer, liver, or kidney diseases or patients who had obstetric complications such as pregnancy induced hypertension, placenta praevia, abruptio placenta, or with any evidence of intrauterine growth retardation or other fetas abnormality were excluded from the study. All operations were performed by the same surgeon. The anaesthesiologist administering the general anaesthesia was not involved with subsequent post-operative patient assessment.

Before surgery, all patients were instructed about the visual analogue scale (VAS) to be used in their assessment.

All women were given oral ranitidine $150 \mathrm{mg}$ [Zantac, Glaxo SmithKline, Egypt] the night before and on the morning of surgery, with 0.3 mol.l-I sodium citrate $(30 \mathrm{ml})$ given 15 minutes beiore operation. In the operating theatre, the women were positioned supine on the operating table with $15^{\circ}$ firm rubber wedge under the right hip to effect left uterine displacement. A 20 gauge cannula was inserted into a forearm vein, and a slow intravenous infusion of 500 $\mathrm{ml}$ lactated Ringer's solution was given over the first 20 minutes.

\section{Study design:}

Patients were allocated randomly to two groups by drawing of sequentially numbered sealed opaque envelopes that each contained a computer-generated randomization code. Placebo group $(n=45)$ received an IV bolus of $20 \mathrm{mI}$ of normal saline $0.9 \%$ followed by a constant infusion $\left(10 \mathrm{ml}^{-\mathrm{hr}^{-1}}\right)$. Ketorolac group $(n=45)$ received an IV loading dose of $20 \mathrm{ml}$ of 
ketorolac tromethamine [Toradol, MUP, Syntex Pharm AG] $\left(0.75 \mathrm{mg}^{-1} \mathrm{ml}^{-1}\right), 20$ minutes before induction of anaesthesia, followed by a constant infusion $\left(10 \mathrm{ml}^{-\mathrm{hr}^{-1}}\right)$ of the same solution until the end of surgery. Both placebo and the ketorolac solution looked the same. The test solution was prepared by one anaesthesiologist, just before induction of anaesthesia, and another anaesthesiologist who was blinded to the solution performed anaesthesia. All the staff in the operating room remained unaware of the randomization code of the patients.

\section{Monitoring:}

The standard monitoring [five leads electrocardiography, non-invasive blood pressure monitoring, pulse oximetry $\left(\mathrm{SpO}_{2}\right)$, and end-tidal carbon dioxide concentration $\left.\left(\mathrm{ElCO}_{2}\right)\right]$ was commenced with Capnomac Ultima monitor (Datex-Ohmeda, Instrumentarium Corp., Helsinki, Finland)

\section{Anaesthesia:}

After 5 minutes of pre-oxygenation, rapidsequence induction of anaesthesia was performed with thiopental 4-6 mg.kgl followed by administration of suxamethonium $1.5 \mathrm{mg} \cdot \mathrm{kg}^{-1}$, after loss of verbal response, to achieve muscle relaxation. Cricoid pressure was applied alter loss of consciousness and was released after correct placement of the tracheal tube had been confirmed. Laryngoseopy was performed after the 1-minute arterial pressure recording, and tracheal intubation wits completed before the 2-minute reading. Mantenance of antasthesia was achieved by a mixture of $0.5 \%$ isofurane and nitrous oxide $50 \%$ in oxygen. Neuromuseular block was maintained with vecuronium $0.06 \mathrm{mg} \mathrm{kg}^{-1}$. The lungs were ventilated I with Ohmeda 7000 ventilator I with a tidal volume of $8 \mathrm{ml.kg}-1$ an inspiration-expiration ratio of $1: 2$ and at a respiratory rate necessary to mantan normocapnia, confirmed by measuring the $\mathrm{EtCO}_{2}$. An inlusion of lactated Ringer's solution $800 \mathrm{ml}$ wats given throughout the procedure. Induction to delivery (I-D) times was recorded by using a stopwatch.

After the umbilical cord was clamped, an infusion of oxytocin 10 i.u. in $500 \mathrm{ml}$ of $5 \%$ glucose was started. Midazolam $0.05 \mathrm{mg} . \mathrm{kg}^{-1}$ and lentanyl $1.0 \mu \mathrm{g}$ $\mathrm{kg}^{-1}$ were given IV and nitrous oxide was increased to $70 \%$. Isoflurane was discontinued at the star of skin closure and nitrous oxide and study drug infusion was discontinued after the last skin suture was applied. At the end of the surgery, residuil neuromuscular block was antagonized with neostigmine $50 \mu \mathrm{g} . \mathrm{kg}^{-1}$ and atropine $20 \mu \mathrm{g} . \mathrm{kg}^{-1}$.

\section{Measurements:}

Heart rate (HR), systolic arterial blood pressure (SBP), and mean arterial blood pressure (MAP) were measured immediately before and at $1,2,3.5,6.10$ minutes after intubation, and at 15. 30 minutes aller delivery; and after extubation.

The obstetrician assessed uterine tome by palpation and rated the degree of uterine contractmm on an unmarked $10-\mathrm{cm}$ visual analogue scalls: (1) indicated none and 10 severe relaxation. If merme tone remained unsatislatetory at 3 minutes, an additional bolus of oxytocin 5 i.u was administered upon the obstentician's request. The intra-operative blood loss was assessed by measuring blood in llo suction botle minus liquor, weighing wet swabs and estimating block on drapes and on the flose. The postoperative transfusion requirements and blend losis were estimaled from nursing inspection of alle perineal pad. was gladed ats (0) small. (1) moderate or (2) lalge. Skin lyy bleceling time (BT) wats determined pre-operatively and $\quad$ lan post-opreratively. 
Stress response was determined by changes in plasma cortisol concentrations. Maternal venous blood samples $(10 \mathrm{ml})$ were collected at three time intervals: preoperatively; 5 minutes after intubation, and 1 hour after clelivery. These times were based on likely physiological responses over time and economic limitations. The blood samples were centrifuged, and serum was drawn off and stored at $4 \mathrm{C}^{\circ}$ until assayed within 2 weeks of collection. Plasma cortisol levels were determined using a radioimmunoassay technique (Gamma Coat@ Cortisol 125 IRIA). The sensitivity was $0.2 \mu \mathrm{g} . \mathrm{dl}^{-1}$ $\left(0.6 \mathrm{nmol} . \mathrm{dl}^{-1}\right)$ and coefficient of variation was $9 \%$.

All neonates were assessed by a single paediatrician who was unaware of the analgesic drug given. Apgar scores were recorded at 1 and 5 minutes. The paediatrician examined each newborn immediately after delivery, after 8, 12, 24 hours in hospital, and 7 days later for any evidence of premature closure of the ductus arteriosus or pulmonary hypertension. The newborns were observed with monitoring of arterial blood pressure, heart rate, temperature and arterial oxygen saturation $\left(\mathrm{SpO}_{2}\right)$.

From the time of extubation, we assessed the severity of post-operative pain on a $10-\mathrm{cm}$ visual analogue scale at rest and with movement, which ranged from 0 for no pain to 10 for the worst pain imaginable, at $0,1,2,4,6,8,10$ and 12 hours after surgery. After operation, tramadol (Tramal) $100 \mathrm{mg}$ IV was prescribed when visual analogue scale scores were 5 or more at rest, and 7 or more with movement or if the patient requested additional analgesia. The time to first request for analgesia and the total analgesic consumption for the first 12 post-operative hours were recorded.

The patients scored the presence and intensity of postoperative side effects as follows: sedation [four-point verbal rating scores (VRS): awake. drowsy, rousable or deep sleep], nausea and vomiting [(0) no nausea, (1) mild-moderate nausea. (2) mild vomiting (once per observation period) with severe nausea, (3) moderate vomiting (twice per observation period), (4) severe vomiting (3-4 times per observation period), or (5) persistent vomiting that needed treatment with an anti-emetic agent] at 0, 1, 2 . $4,6,8,10$ and 12 hours after surgery. and intra-operative recall.

\section{Statistical analysis}

Statistical analysis was performed using Statistic:. '99 software (StatSoft, Tulsa, Okla.). Data were testec for normality using Kolmogorov-Smirnov test. Un-paired Student's t test was performed to compare the parametric values of the two groups. Mann Whitney $U$ test was performed to compare the non-parametric values of the two groups. Serial changes in haemodynamic and cortisol data at induction were analyzed with repeated measures analysis of variance. Data were expressed as frequency, mean $\pm S D$, percentage or median (range). A value of $\mathrm{P}<0.05$ was considered to represent statistical significance.

Based upon our preliminary data, a prior power analysis indicated that 45 patients in each group would be a sufficiently large sample size to be adequate to detect a $20 \%$ reduction in post- induction blood pressures values, with a type-I error of 0.05 and a power of approximately $90 \%$.

\section{RESULTS}

\section{Maternal Data:}

All 90 patients completed the study period: 45 patients in the placebo group, and 45 in the ketorolac group. Maternal age, weight, height, gestational age. I-D time, anaesthesia time, and estimated weight of 
the fetus, did not significantly differ between the groups [Table (I)].

Baseline HR, SBP and MAP were similar between the two groups [Figures $(1,2,3)$ ]. The changes in HR from baseline values after tracheal intubation (at 2, 3, 4, 5, 6, and 10 minutes), and at 15 minutes after delivery were significantly greater in the placebo group than in the ketorolac group $(\mathrm{P}<0.001)$ [Figure (1)].

The changes in SBP and MAP from baseline values after tracheal intubation (at 1, 2, 3, 4, 5, 6, and 10 minutes), and at 15 minutes after delivery were significantly greater in the placebo group than in the ketorolac group $(P<0.001)$ [Figures $(2,3)$ ]. HR, SBP, and MAP increased after intubation and returned to baseline levels by 3-4minutes in both groups $(\mathrm{P}<0.01)$ [Figures $(1,2,3)]$.

The placebo group had a significantly higher pain scores [VAS] at rest and on movement, than did the ketorolac group for the lirst 2 hours following surgery $(\mathrm{P}<0.001)$ [Table (II)]. The time to first tramadol request in the ketorolac group [3.0 \pm 1.45 hours] was significantly longer than in the placebo group $[1.2 \pm 0.994$ hours $](P=0.001)$ [Table (III)]. Additionally, the median doses of tramadol consumption for the first 4 hours after surgery were significantly higher in the placebo group than in the ketorolac group $(\mathrm{P}=0.004)$ [Table (III)]. VRS scores for sedation were similar in the two groups [Table (III)].

Baseline maternal cortisol concentrations in the placebo group, $28.2 \pm 11.4 \mu \mathrm{g}$. $\mathrm{dl}^{-1}$, were similar to those in the ketorolac group, $27.8 \pm 11.25 \mu \mathrm{g} . \mathrm{dl}^{-1}$, Five-minutes after intubation and $I$ hour after delivery, cortisol concentrations were significantly greater in the placebo group $\left[45 \pm 15.1 \mu \mathrm{g}\right.$. $\mathrm{dl}^{-1}$ and $43 \pm 13.3 \mu \mathrm{g} . \mathrm{dl}^{-1}$, respectively], compared with the ketorolac group $\left[32.2 \pm 7.61 \mu \mathrm{g} . \mathrm{dl}^{-1}\right.$, and $32.33 \pm$
$10.3 \mu \mathrm{g} . \mathrm{dl}^{-1}$, respectively], $(\mathrm{P}=0.032$ and 0.014 . respectively) [Figure (4)].

The surgeon's VAS assessment of uterinc relaxation indicated that there was no significant difference between the two groups [Table (IV)]. $15.6 \%$ of patients $[7 / 45]$ in the ketorolac group and $11.1 \%$ of patients [5/45] in the placebo group required supplementary doses of oxytocin, but this difference was not significant [Table (IV)] Additionally, the peri-operative blood loss wats similar in both groups and no patient required blood transfusion [Table (IV)]. Pre-operative and post-operative bleeding times did not change significantly in both groups [Table (IV)].

There were no reported serious side effects during this study. There were no differences between groups with respect to the frequency and severity of nausea and vomiting [Table (IV)]. None of the mothers complained of intra-operative recall.

\section{Neonatal Data:}

The Apgar scores at 1 and 5 minutes were similar in ketorolac and placebo groups [Tahle (IV)]. Additionally, there were no reported postoperattive differences in the follow-up examination of the cardiovascular status, evidence of premature closure of the ductus arteriosus or pulmonary hypertension of the newborns in both groups.

\section{DISCUSSION}

The sympathetic responses [hypertension and tachycardia] to laryngoscopy and tracheal intubation and their pharmacological modifications have been well documented. The present study demonstrates that administration of ketorolac prior to Caesarean delivery resulted in lower increases in HR, SBP, MAP, and cortisol levels, in response to endotracheal intubation, and better postoperative analgesia without 
adverse neonatal outcome.

Opioids ate an integral component of getueral anaesthetic techniques for major surgery. They attenuate the haemodynamic and catecholamine ("stress") response to tracheal intubation(7), and may provide preemptive analgesia to reduce postoperative pain ${ }^{(8)}$. However, maternatly administered opioids may cross the placenta and adversely affect the neonate $(9)$.

The analgesic effects of NSAIDs have been investigated in patients after Caesarean section $(3,4,6)$. No studies have investigated the effects of preemptive ketorolac afte! Cesarean delivery.

The intra-operative lower values of $\mathrm{HR}, \mathrm{SBP}$, MAP, and cortisol levels, after intubation, in our ketorolac group were similar to those reported in previous studies. El-Hakim and coworkers found that pre-mptive tenoxicam is an effective pretreatment to minimize the haemodynamic variability of light general anacsthesia at induction-delivery and in improvement of post-operative analgesia, with slight increase in blecding time in Cesarean delivery patients $(4.10)$. Moreover, rectal Ibuprofen (500 mg) pre-treatment in peri-operative course is able to reduce the enderine response and cylokine release 11 !

NSAIDs act by anti-inllanmation. They inhibit the production of prostaglandins and they decrease pain by inhihiting phosphodiesherase enzyme which increase cyclic AMP in the white blood cells, so white blood cells decreatse the release of prostaglandins, leukotrienes, braklyinin, serotonin and histamine which will decrease pain at the periphery (2).

The present study showed improved analgesia and decreased tamadol consumption with a lower incidence of sedalion for the first 4 post-operative haurs by using ketorolac aller Caesarean section, which may coincide with the duration of action of the drug intusion. Previous studies have adminstered IM ketorolac after Caesarean celivery and found that ketorolac has similar efficacy to IM meperidine. but ketorolac produced lewer side effects ${ }^{13}$ ). In addition, Ketorolac proved to have morphine sparing effect. improve analgesia, reduce opioid requirements, and also reduced the incidence of the pruritus, nausea vomiting, constipation, sedation or respiratory depression commonly associated with opioids (14). Therefore, ketorolac had the potential 10 replace opioids in the treatment of severe pain.

Platelet inhibition with altered haemostasis i among the list of adverse eflects associated with the adminisuation of ketorolac. In addition oher concluded that hacmostasis was significantly mort difficult to achieve in patients receiving ketorolax (15-16). In the present study, we found no evidence of increased peri-operative blood loss in those receiving ketorolac. Similarly, El-Hakim and others concluded that during Caesarean delivery IV tenoxicam causes a slight increase in bleeding lime with no significant changes in platelet marker levels. and the extent of uterine relaxation or bleeding $(4,10)$. In addition, others reported that plateles function. by Ivy bleeding time, platelet aggregrometry. and thromboelastography. Was not inhibited aller IV kecorolac despite near complete abolition of serum thromboxane $\mathrm{B}_{2}\left(\mathrm{TxB}_{2}\right)$ productonon ${ }^{(17)}$. Extemsive post-marketing surveillance indicates a very small risk of gastrointestinal or operative site hleding. (with no significant increatse) compared with opiorich. when appropriate doses are used in youne alull populations ${ }^{(18)}$. Severa! studies have used smple' hut clincially relevant. assessments ol vaginal bland loss or the ned for oxytocics either intal- w postoperatively and reputed no significant cllicl

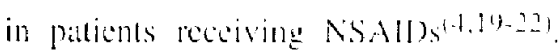


NSAIDs are known to induce premature closure of the patent ductus arteriosus when given in large doses to mothers before delivery. In the current study, there was no reported evidence of premature closure of the ductus arteriosus or pulmonary hypertension of the newborns in both groups. Similarly, several studies reported no difference in neonatal outcome, as determined by Apgar scores and blood gas analyses with the pre-operative use of IV tenoxicam or postoperative Caesarean delivery pain relief ${ }^{23)}$. Vermillion and others' reported that in 61 cases in which the pregnant women were treated for preterm labor with indomethacin $(25 \mathrm{mg}$ orally every 6 hours), a dramatic yet reversible increase in the incidence of indomethacin-induced ductal constriction occurs at 31 weeks' gestation. However, after discontinuation of indomethacin therapy, all follow-up cchocardiograms demonstrated a return to non-constricted ductal flow velocities, with no significant adverse neonatal outcomes ${ }^{(24)}$. Morcover, the transfer of ketorolac into breast milk has becn quantified, and it is considered to be safe for use during lactation ${ }^{(25)}$. Thus, a possible explanation could be thiat, we used relatively small doses of ketorolac for limited periods of continuous IV infusion.

In conclusion. in this study pre-emptive IV ketorolac is sale and eflective in attenuating the maternal stress response with improved the quality of post-operative analgesia in Caesarean delivery patients, with no adverse neonatal outcome.

Limitations to our study:

Further multi-center studies are needed to define the efficacy and the safety of the use of pre-operative ketorolac in pregnant patients undergoing Caesarean delivery for the attenuation of the stress response and evaluate the neonatal outcome.

\section{REFERENCES}

1. Gin T, O'Meara ME. Kan AF, Leung RKW, et al: Plasma catecholamines and neonatal condition after induction of anaesthesia with propofol or thiopentone at Caesarean section. Br J Anaesth 1993; 70:311-317.

2. Gin T, Ngan-Kee WD, Siu YK. Suart JC, et al: Alfentanil given immediately before the inductuon of anesthesia for elective Cesarean delivery. Anesth Analg 2000; 90:1167-1172.

3. Olofsson CI, Legeby MH, Nygards EB, and Osuman KM: Diclotenac in the teatment of pain alter Caesarean delivery. An opioid-saving strategy. Eur J Obstel Gynecol Reprod Biol 2000; 88(2): 143-149.

4. El-Hakim $M$ and Nafie $M$ : I.v. tcnoxicam for analgesia during Caesarean section. $\mathrm{Br} \mathrm{J}$ Anilesih 1995; 74:643-646.

5. Gillis JC and Brogden RN: Ketorolac: A retipprassal of its pharmacodynamic and pharmacokunetic propertics and therapcutic use in pain managemen Drugs 1997; 53: 139-188.

6. Lowder IL, Shackellord DP, Holbert D, and Beste TM: A randomized, controlled trial to compare ketorolac tromethamine versus placebo after Cesarean section to reduce pain and narcolic usage Am J Obstet Gynecol 20(3): 189:1559 - 1562.

7. Kovac AL: Controlling the hemodynamic response (1) laryngoscopy and endotracheal intubation. J Clin Anesth 1996; 8:63-79.

8. Kissin I: Preemptive analgesia: why its effect is not always obvious. Anesthesiology 1996; 84:1015-1024.

9. Krishna BR, Zakowski MI, and Grant GJ: Sulentanil transier in the human placenta during in vitro perfusion. Can J Anacsth 1997; 44(9): 996-1001.

10. El-Hakim M. Fathy A, Amine H. Saeed A. and Mckawy $M$ : Eflect of i.v. tcnoxicam during Caesarean clelivery on platelet activity. Acta Anacsthesiol Scand 2000; 44(5):555-563.

11. Chambricr C. Chassard D, Bienvenu J, Saudin F, ct al: Cytokine and hormonal changes after cholecystectomy. Elfect of ibuprofen pretreatunent. Ann Surg 1997 Jul; 226(1):110-111.

12. Moote CA: The prevention of post operative pain. Can J Anacsth 1994; 41: 527-33. 
13. Gin T, Kan AF, Lam KK, and O'Meara ME: Amalgesia after Caesarean section with intramuscular ketorolac or pethidine. Anaesth Intensive Care 1993; 21: 420-423.

14. Jelinek GA: Ketorolac versus morphine for severe pain: Ketorolac is more ellective. cheaper, and has fewer side effects. BMJ 2000; 321 (7271):1236-1237.

15. Rusy LM, Houck CS. Sullivan LJ, OhIms LA, Jones DT, et al: $\Lambda$ double-blind evaluation of ketorolac tromethamine versus acetaminophen in pediatric tonsillectomy: analgesia and blceding. Anesth Analg 1995, 80, 226-229.

16. Jones SF: NSAID for cacsarean section. $\mathrm{Br} J$ Anacsth 1995: 75:666-669.

17. Thwaites BK. Nigus DB, Bouska GW. Mongan PD. ct al: Intravenous ketorolac tromethamine does nol worsen platelet lunction during knce arthroscopy under general ancsthesia. Anesth Analy 1995: 81. $119-124$.

18. Strom BL. Berlin JA. Kinman JL, el al: Parenteral ketorolac and risk of gatstrointestimal and operative sile hleeding: a post-markcling surveillance study. JAMA 1496: 275: 376-382.

19. Tzeng II and Mok MS: Combination of intramuscular ketorolac and low dose epidural morphine for the relief of post-Cacsarcan pain. Ann
Acull Med Singapore 1994: 23: 10-13.

20. Sia ATH. Thomas E, Chong JL. and Loo CC: Combination of suppository diclofenac and intravenous morphine infusion in post-Caesarcan section pain relicf - a step towards balanced analgesia? Sing Med J 1997; 38: 68-70.

21. Rorarius MGF, Suominen P, Baer GA, et al: Diclofenac and keloproten for pain treatmem at ter clective Caesarean section. Br J Anacsila 1993; 70 : 293-300.

22. Mogensen T, Vegger P. Jonsson T, et al: Systemic piroxicam as an adjunct to combined cpiclural bupivacaine and morphine for postoperative pain relief-a double-blind study. Anesth Analg 1992; 74: 366-370.

23. Belzarena SD: Evaluation of intravenous tenoxkam for postoperative Cesarcan delivery pain relicf. Proliminary report. Reg Anesth 1994: 19 (6):408-411.

24. Vermillion ST, Scardo JA, Lashus AG, and Wiless HB: The effect of indomethacin tocolysis on letal ductus arteriosus constriction with advancing gestational age. Am J Obstet Gynecol 1947: 177 (2):256-9: 259-61.

25. Rathmell JP, Viscomi CM, and Ashburn MA: Management of nonobsletric pain during pregmancy and latchation. Anestl Analg 1997: 85: 1074-1067. 
Table I : Demographic data of the patients in ketorolac group and placebo group. Data are expressed as $[$ mean $\pm \mathrm{SD}]$.

\begin{tabular}{|l|c|c|}
\hline & $\begin{array}{c}\text { Second group } \\
(\mathbf{n}=72)\end{array}$ & P value \\
\hline Age (Years) & $27.1 \pm 4.18$ & $26.2 \pm 5.10$ \\
\hline Weight (Kg) & $78.6 \pm 7.96$ & $77.7 \pm 10.78$ \\
\hline Height (cm) & $162 \pm 3.35$ & $160 \pm 2.23$ \\
\hline Gestational age (weeks) & $38.9 \pm 1.51$ & $39.3 \pm 1.71$ \\
\hline I-D time (minutes) & $11.4 \pm 1.76$ & $10.8 \pm 1.47$ \\
\hline Anaesthesia time (minutes) & $39.7 \pm 5.26$ & $41.8 \pm 5.63$ \\
\hline Birth weight (Kg) & $3.3 \pm 0.26$ & $3.2 \pm 0.19$ \\
\hline
\end{tabular}

I-D time $=$ Induction to delivery time (minutes)

* Significant when $P<0.05$.

Table II : Visual analogue scale (VAS) assessment of post-operative pain, at rest and with movement in the studied groups. Data are expressed as [median (range)].

\begin{tabular}{|c|c|c|c|c|}
\hline & \multicolumn{2}{|c|}{$\begin{array}{l}\text { Placebo group } \\
(\mathbf{n}=45)\end{array}$} & \multicolumn{2}{|c|}{$\begin{array}{l}\text { Ketorolac group } \\
\qquad(\mathrm{n}=45)\end{array}$} \\
\hline & At rest & On movement & At rest & On movement \\
\hline post-exubation & $4(1-8)$ & $7(4-10)$ & $2(0-6)^{*}$ & $5(3-9)^{k}$ \\
\hline 1 hour & $6(2-7)$ & $9(5-10)$ & $2(1-6)^{*}$ & $5(4-9)^{*}$ \\
\hline 2 hours & $4(3-7)$ & $7(6-10)$ & $2(0-6)^{*}$ & $5(3-9)^{k}$ \\
\hline 4 hours & $3(1-6)$ & $6(7-9)$ & $5(0-7)$ & $8(3-10)$ \\
\hline 6 hours & $2(0-4)$ & $5(3-7)$ & $2(0-6)$ & $5(3-9)$ \\
\hline 8 hours & $1(0-8)$ & $1(0-8)$ & $3(0-6)$ & $3(0-6)$ \\
\hline 10 hours & $2(0)-6)$ & $5(3-9)$ & $2(0-7)$ & $5(3-10)$ \\
\hline 12 hours & $2(0-9)$ & $5(3-10)$ & $1(0-8)$ & $4(3-10)$ \\
\hline
\end{tabular}

$\because P<0.05$ Significan when compared with the placebo group. 
Table III: The time to first request for analgesia, the post-operative hourly tramadol consumption, and verbal rating score (VRS) for sedation in the studied groups. Data are expressed as $[$ mean $\pm \mathrm{SD}$ or median (range)].

\begin{tabular}{|l|c|c|c|}
\hline & $\begin{array}{c}\text { Placebo group } \\
(\mathbf{n}=45)\end{array}$ & $\begin{array}{c}\text { Ketorolac group } \\
(\mathbf{n}=\mathbf{4 5})\end{array}$ & P value \\
\hline $\begin{array}{l}\text { The time to first request for analgesia (hours) } \\
\text { The post joperative hourly tramadol }\end{array}$ & $1.2 \pm 0.94$ & $3.0 \pm 1.45$ & $0.00)^{*}$ \\
consumption (mig) & $100(0-100)$ & $0(0-100)$ & $0.004^{*}$ \\
\hline - 4 hours & $100(0-200)$ & $100(0-300)$ & 1.000 \\
$4-8$ hours & $100(0-200)$ & $100(0-200)$ & 0.724 \\
$8-12$ hours & $2(2-3)$ & $1(0-3)$ & 0.206 \\
The verbal rating score (VRS) lor sedation & $0(0-1)$ & $0(0-1)$ & 0.534 \\
0 hours & $0(0-0)$ & $0(0-0)$ & 1.000 \\
1 hours & $0(0-0)$ & $0(0-0)$ & 1.000 \\
2 hours & $0(0-0)$ & $0(0-0)$ & 1.000 \\
4 hours & $0(0-0)$ & $0(0-0)$ & 1.000 \\
8 hours & $0(0-0)$ & $0(0-0)$ & 1.000 \\
10 hours & $0(0-0)$ & $0(0-0)$ & 1.000 \\
\hline 12 hours & & & \\
\hline
\end{tabular}

$* P<0.05$ Significatn when compared with the placebo group.

Table VI : The Peri-operative data. Data are expressed as [median (range), percentage\% (numbers) or mean $\pm S D]$.

\begin{tabular}{|c|c|c|c|}
\hline & $\begin{array}{l}\text { Placebo group } \\
\qquad(n=45)\end{array}$ & $\begin{array}{l}\text { Ketorolac group } \\
\qquad(\mathrm{n}=45)\end{array}$ & P value \\
\hline VAS assessment of uterine relaxation & $3(0-3)$ & $3(0-3)$ & 0.851 \\
\hline $\begin{array}{l}\text { Percentage of the patients needed } \\
\text { supplementary doses of oxytocin (i.u) }\end{array}$ & $11.1 \%(5 / 45)$ & $15.6(7 / 45)$ & 0.772 \\
\hline The intra-operative blond loss $(\mathrm{ml})$ & $279 \pm 88.97$ & $298 \pm 89.95$ & 0.557 \\
\hline The postoperative blood loss & $0(0-2)$ & $0(0-3)$ & 1.000 \\
\hline BT (minutes): Pre-operative & $3.6 \pm 1.24$ & $3.4 \pm 1.18$ & 0.655 \\
\hline Post-operative & $3.7 \pm 1.05$ & $3.7 \pm 0.96$ & 0.857 \\
\hline $\begin{array}{l}\text { Percentiage of the patients suffered from nauseal } \\
\text { and vomiling } \\
\text { The post-operative score for natasea and vomiting }\end{array}$ & $11.1 \%(5 / 45)$ & $6.7 \%(3 / 45)$ & 1.0100 \\
\hline 0 hours & $0(0-3)$ & $0(0-1)$ & 1.000 \\
\hline 1 houts & $0(0)-1)$ & $(0(0-3)$ & 1.000 \\
\hline 2 hours & $0(0-1)$ & $0(0-1)$ & $1.0(0)$ \\
\hline 4 hours & $0(0-3)$ & $0(0-1)$ & $1.0(0)$ \\
\hline 6 hours & $(0)(0-1)$ & $0(0-1)$ & 1.000 \\
\hline 8 hous & $0(0-1)$ & $0(0-1)$ & 1.0011 \\
\hline lo houss & $0(0-1)$ & (0) $(0-0)$ & $1.0(0)$ \\
\hline 12 hours & $0(0-1)$ & $0(0-1)$ & $1.0(0)$ \\
\hline Apgar score: 1 minutes & $8(5-10)$ & $7(4-10)$ & $1.0(1)$ \\
\hline 5 minutes & $10(9-10)$ & $10(9-10)$ & $1.000)$ \\
\hline
\end{tabular}

$* \mathrm{P}<0.05$ Significaln when comprared with the placebo group. 


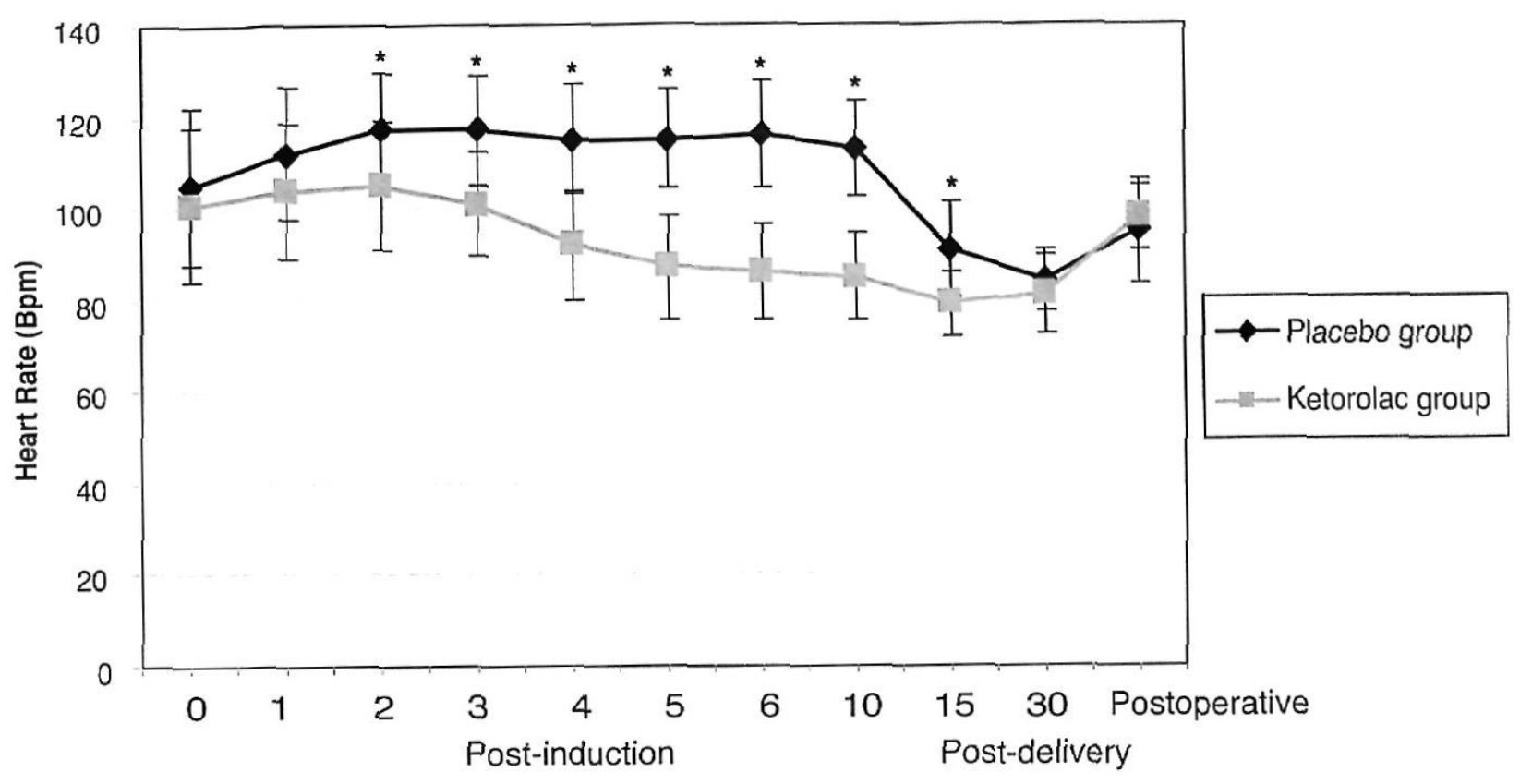

Time (minutes)

${ }^{\star} \mathrm{P}<0.05$ when compared with placebo group.

Figure (1) : Perioperative heart rate $[\mathrm{Bpm}]$ changes in the studied group [mean $\pm \mathrm{SD} \mid$.

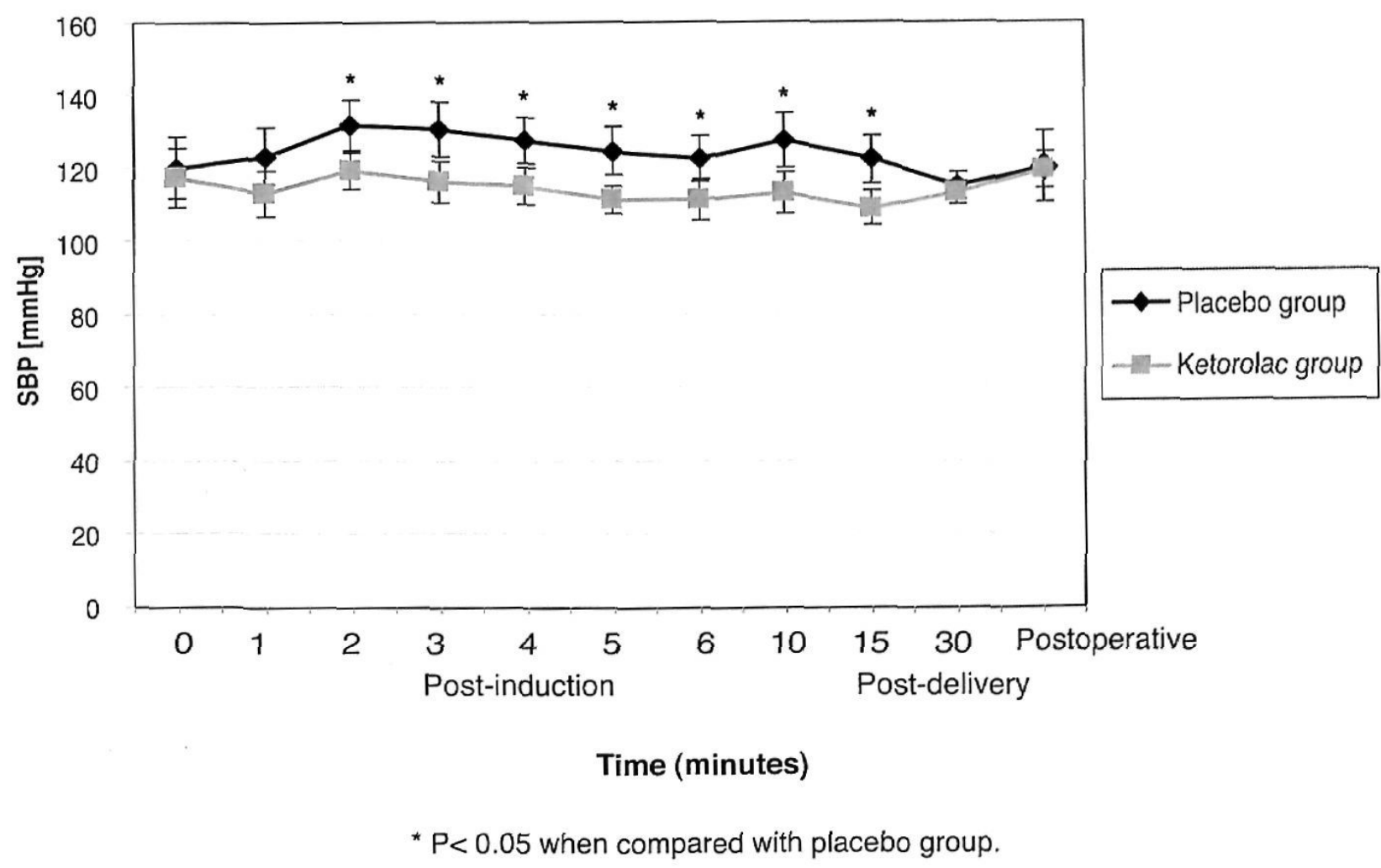

Fig. 2. Perioperative systolic arterial blood pressure (SBP) $[\mathrm{mmHg}]$ changes in the studied groups [mean \pm SD]. 


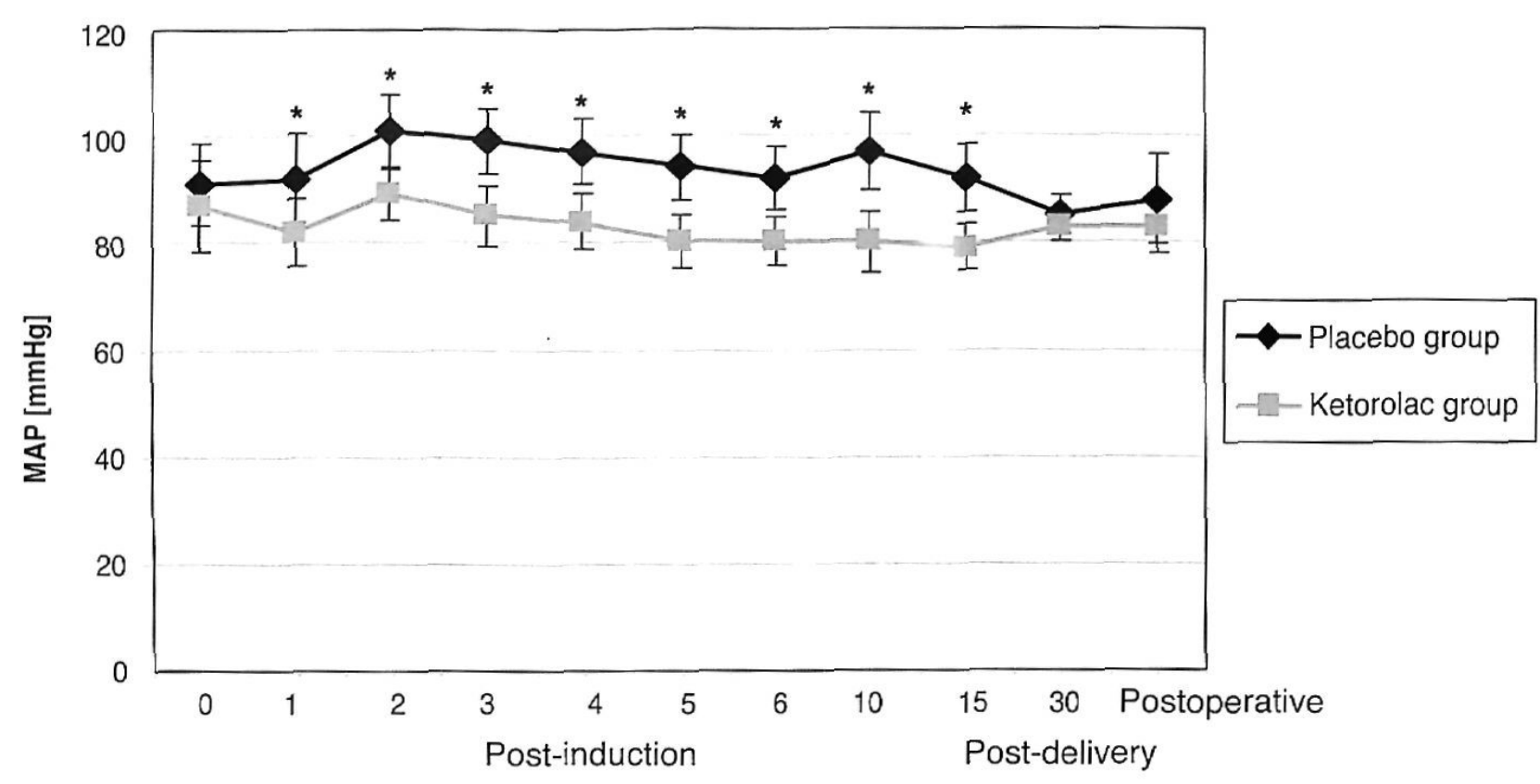

Time (minutes)

${ }^{\star} \mathrm{P}<0.05$ when compared with placebo group.

Figure (3) : Perioperative mean arterial blood pressure (MAP) [mmHg] changes in the studied groups [mean \pm SD].

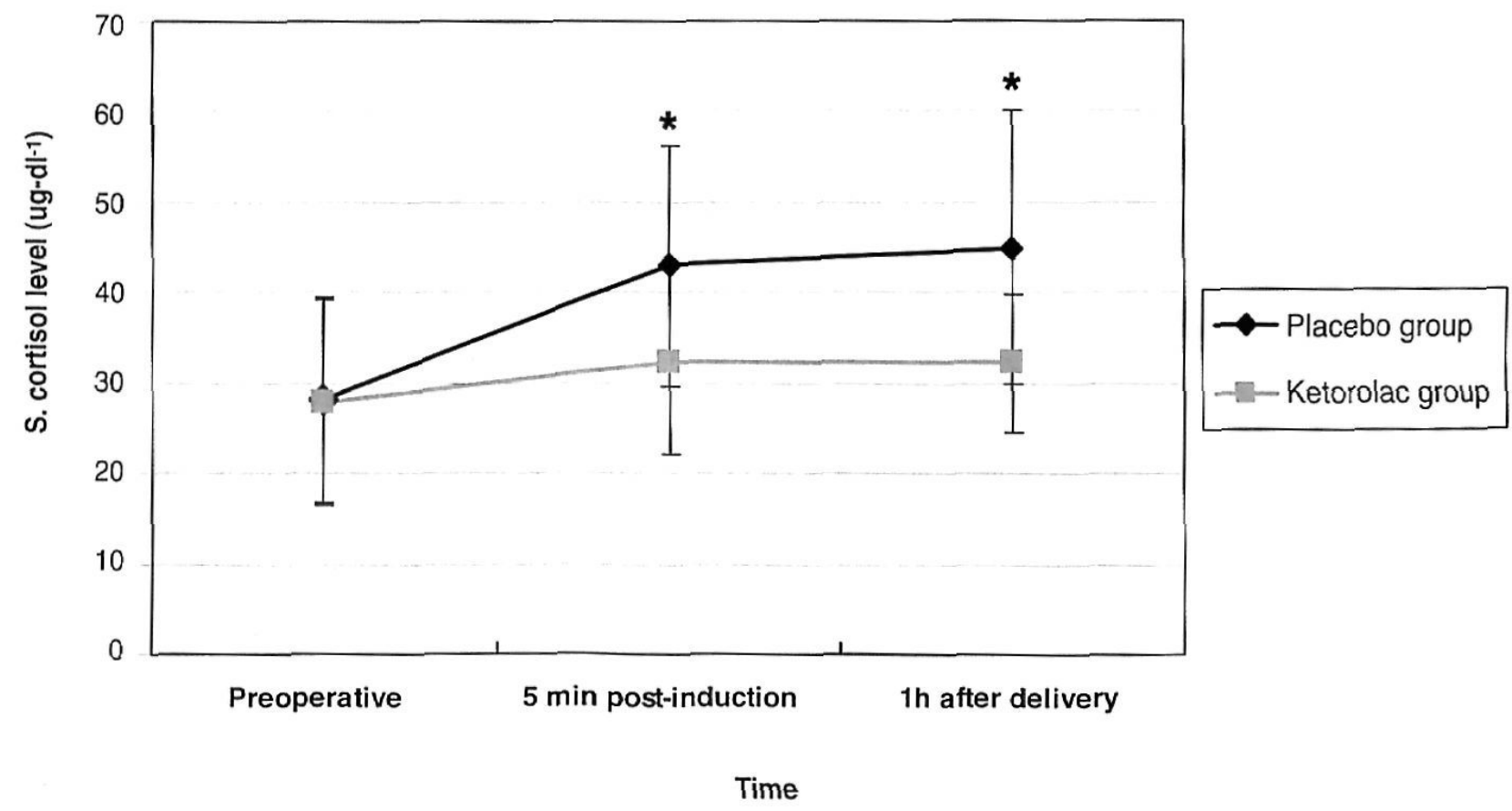

${ }^{*} \mathrm{P}<0.05$ when compared with placebo group.

Fig. 4. Serum cortisol level changes in the studied groups. Data are expressed as [mean $\pm S D]$. 